\title{
Family-based treatment of eating disorders in adolescents: current insights
}

REVIEW

This article was published in the following Dove Press journal:

Adolescent Health, Medicine and Therapeutics

I June 2017

Number of times this article has been viewed

\author{
Renee D Rienecke ${ }^{1-3}$ \\ 'Department of Pediatrics, \\ ${ }^{2}$ Department of Psychiatry and \\ Behavioral Sciences, College of \\ Medicine, Medical University of \\ South Carolina, Charleston, SC, \\ ${ }^{3}$ Department of Psychiatry, University \\ of Michigan Health System, Ann Arbor, \\ MI, USA
}

\begin{abstract}
Eating disorders are serious illnesses associated with significant morbidity and mortality. Family-based treatment (FBT) has emerged as an effective intervention for adolescents with anorexia nervosa, and preliminary evidence suggests that it may be efficacious in the treatment of adolescents with bulimia nervosa. Multifamily therapy for anorexia nervosa provides a more intensive experience for families needing additional support. This review outlines the three phases of treatment, key tenets of family-based treatment, and empirical support for FBT. In addition, FBT in higher levels of care is described, as well as challenges in the implementation of FBT and recent adaptations to FBT, including offering additional support to eating-disorder caregivers. Future research is needed to identify families for whom FBT does not work, determine adaptations to FBT that may increase its efficacy, develop ways to improve treatment adherence among clinicians, and find ways to support caregivers better during treatment.
\end{abstract}

Keywords: eating disorders, adolescents, family-based therapy, anorexia nervosa, bulimia nervosa

\section{Introduction}

Eating disorders are serious psychiatric illnesses that generally develop during adolescence, and are associated with significant medical and psychological sequelae. Anorexia nervosa (AN) is characterized by significantly low body weight, fear of weight gain or behavior that interferes with weight gain, and disturbance in the way one's body weight or shape is experienced, overvaluation of shape and weight, or lack of recognition of the seriousness of the low body weight. Lifetime prevalence rates of AN and subthreshold AN among adolescents are $0.3 \%-0.6 \%$ and $0.6 \%-0.8 \%$, respectively. ${ }^{1,2}$ High rates of comorbidity are found among patients with $\mathrm{AN}$, with approximately $50 \%$ meeting criteria for another psychiatric disorder. ${ }^{2,3} \mathrm{AN}$ is associated with impaired quality of life ${ }^{4}$ and significantly elevated mortality rates that are among the highest of any psychiatric illness. ${ }^{5,6}$

Bulimia nervosa $(\mathrm{BN})$ is characterized by recurrent episodes of eating that are accompanied by a sense of loss of control, as well as inappropriate compensatory behavior and overvaluation of shape and weight. ${ }^{7}$ Lifetime prevalence rates of BN and subthreshold BN among adolescents are $0.9 \%$ and $6.1 \%$, respectively. ${ }^{1,2}$ Almost $90 \%$ of patients with BN meet criteria for another co-occurring psychiatric disorder, ${ }^{2}$ and $\mathrm{BN}$ is associated with high rates of impairment and suicidality. Binge-eating disorder is characterized by binge-eating episodes that are not accompanied by inappropriate compensatory behavior, but are associated with marked distress. Prevalence rates for binge-eating disorder are $1.6 \%$ among adolescents. ${ }^{2}$ Avoidant/restrictive food-intake
Correspondence: Renee D Rienecke Medical University of South Carolina, 26I Calhoun Street - 220, Charleston, SC 2940I, USA

Tel + I 8437928157

$\mathrm{Fax}+\mathrm{I} 8438768462$

Email rienecke@musc.edu 
disorder (ARFID), introduced as a new disorder in the fifth edition of the Diagnostic and Statistical Manual of Mental Disorders (DSM-5), ${ }^{7}$ is characterized by an eating or feeding disturbance resulting in significant weight loss or failure to achieve expected weight, nutritional deficiencies, dependence on enteral feeding or nutritional supplements, or interference with psychosocial functioning. Prevalence estimates range from $5 \%{ }^{8}$ to $22.5 \%,{ }^{9}$ depending on the treatment setting.

A substantial number of individuals experience clinically significant difficulties with eating that do not meet criteria for one of the aforementioned diagnoses. ${ }^{2,10,11} \mathrm{~A}$ diagnosis of other specified feeding or eating disorder is given in these cases. Despite the subthreshold nature of this diagnosis, patients who do not meet full criteria for an eating disorder are still medically compromised ${ }^{11}$ and often do not differ in clinically significant ways from their full-threshold counterparts. ${ }^{12,13}$ Approximately 13\% of adolescents will develop an eating disorder by the age of $20 .{ }^{14}$ Eating disorders have been reported to be the third-most common chronic condition among adolescents, behind obesity and asthma. ${ }^{15}$

\section{Family-based treatment for AN}

Research on the treatment of eating disorders in adolescents has lagged behind that of adults, but family-based treatment (FBT), also sometimes known as the Maudsley method or Maudsley approach, has emerged as an effective intervention and is considered by some to be the treatment of choice for adolescents with AN who are medically stable and fit for outpatient treatment. FBT is a manualized outpatient therapy designed to restore adolescents to health with the support of their parents. ${ }^{16}$ The treatment for AN consists of three phases. Phase 1 focuses on the rapid restoration of physical health, orchestrated by parents. It is explained to families that because of the ego-syntonic nature of the disorder, the patient on his or her own will have difficulty making healthy decisions about food and eating. In an effort to keep patients out of higher levels of care, decisions about eating are temporarily taken out of their hands and given to parents. Parents are given responsibility for deciding what their child eats, how much is eaten, when it is eaten, monitoring all food intake, and generally curtailing physical activity, much like the treatment team would do on an inpatient unit. The goal of FBT, however, is to allow patients to recover in their day-to-day environment with their support system around them, rather than separating them from their parents by sending them to an inpatient or residential treatment program. Siblings are given a supportive role in treatment, and are not included in the parents' job of weight restoration.
The second session of FBT consists of a family meal, in which the family brings a meal into the therapist's office and the therapist begins to instruct the family in ways to be more effective with both the eating disorder and their child. The purpose of the family meal is to give parents, who at this point are often feeling quite defeated by the eating disorder, a taste of success in encouraging their child to eat more than he or she had originally intended.

Phase 1 continues until there is steady weight gain, the eating disorder has begun to recede, and the child is eating without much resistance to parental involvement. Phase 2 involves gradually giving responsibility over eating back to the adolescent, to whatever extent is age-appropriate and normal for a particular family. This phase is conducted gradually, in order to minimize the chances of backsliding, which can be disheartening to families and therapists alike. For example, rather than having parents serve a child at dinner as they would during phase 1 , the child may begin to serve himself or herself, with parental oversight in place and the understanding that parents will add food if they deem what the child chose to be inadequate.

In Phase 3, there is a review of adolescent development, and the therapist ensures that the family is back on track with normal family life. The family identifies upcoming developmental challenges that the adolescent must face, and identifies how to help the young person navigate these challenges without reverting to the eating disorder as a way to cope.

\section{Family-based treatment for BN}

FBT has been adapted for use with patients with BN. ${ }^{17}$ Although it shares several similarities with FBT-AN, the main focus of FBT-BN is on interrupting the pattern of binge eating and purging. Although parents are still in charge of recovery, the approach tends to be more collaborative in nature. This is possible in part because of the more ego-dystonic nature of the illness when compared to AN. Care is taken to modify parental criticism, which may be higher in families of a patient with $\mathrm{BN}$ than with $\mathrm{AN},{ }^{18}$ and to reduce the shame and secrecy commonly surrounding binge-eating and purging behaviors. In addition, there is somewhat more flexibility in the approach, allowing for a shift in focus to address comorbid illnesses or behavioral problems that may present themselves more often than is usually the case in the treatment of AN.

\section{Family-based treatment for other eating and weight disorders}

FBT has also been adapted for use with prodromal presentations of AN,,${ }^{19}$ pediatric obesity (PO), ${ }^{20}$ and ARFID. ${ }^{21}$ In 
comparison to FBT-AN, the emphasis in FBT for prodromal AN shifts from rigorous weight restoration to normalization of eating habits and efforts to prevent the development of full-blown AN. ${ }^{19}$ There is also a focus on implementation of regular family meals and modeling of healthy eating by parents.

In FBT-PO, treatment approaches are modified according to the age of the patient. ${ }^{20}$ Parents are involved at the beginning of treatment to varying degrees, depending on whether the patient is a child, preadolescent, or adolescent, and parental control over eating and exercise lessens over the course of treatment. For children in FBT-PO, parental involvement at the beginning of treatment may look very similar to FBT-AN, in that parents take full responsibility for all eating-related decisions and monitor all meals and snacks. However, in FBT-PO, parents would also initiate physical activity.

In FBT-ARFID, the focus of treatment is on helping parents increase the types and variety of food consumed by the patient. ${ }^{21}$ There is an emphasis on educating the parents about the factors unique to ARFID, such as the mechanisms that keep children from trying new foods and the frequency with which new foods need to be presented. These adaptations to FBT appear promising, but data are needed to determine the efficacy of FBT for different populations.

\section{Key tenets of family-based treatment}

There are several key tenets of FBT that are important to keep in mind when working with families. These tenets set FBT apart from many other schools of thought when it comes to treating eating disorders. First, FBT takes an agnostic view of the cause of the illness, ie, no assumptions are made about the potential causes of eating disorders. ${ }^{16}$ Instead, they are viewed as complex and multifactorial illnesses, with many different critical factors needing to "fall into place" for an eating disorder to develop. The focus of FBT is not on identifying these various factors, but on identifying what needs to be done to help the adolescent move forward with recovery as quickly as possible. The adolescent is not blamed for developing the illness, while it is also made clear to families that parents are not to blame for causing the illness.

Second, there is a focus on externalizing the illness from the patient. It is emphasized that the eating disorder and the child are not one and the same. The eating disorder has "taken over" the child when it comes to issues of food, eating, shape, and weight, and in those instances it is driving the child's thoughts, feelings, and behaviors. Parents must know that their child is not in control of the disorder, and just as they did not choose to develop the disorder, they cannot choose to stop the eating-disordered behavior. Externalization serves several purposes, one of which is to reduce parental criticism, which has been shown to have a negative impact on treatment outcome. ${ }^{22-26}$

A third tenet is that the therapist takes a nonauthoritarian therapeutic stance when working with the family. The therapist takes an active role in guiding the family through the recovery process, but does not tell the family exactly how to go about helping their child recover. Rather, the therapist joins the family in helping them figure out for themselves the best way to refeed their child. There is no one-size-fits-all approach in FBT. Families are told that they are in charge of weight restoration, but they are not given an exact plan for how to accomplish this. While the therapist is seen as an expert consultant, the parents are seen as the experts on their family, with knowledge about the family's likes, dislikes, habits and routines, preferences, and ethnic, religious, and cultural backgrounds, all things that can impact a family's eating patterns. Therefore, they are in the best position to come up with a plan for helping their child recover.

Empowerment of the parents is another tenet of the treatment approach. In FBT, parents are in no way thought to be responsible for causing the eating disorder. ${ }^{27}$ Rather, FBT views parents as their child's best resource for recovery and the main agents of change in the therapeutic process. To be successful in overcoming the eating disorder, parents must feel confident in their interactions with their child and with the eating disorder. The therapist works to empower parents by putting them in charge of the process and communicating to them that the therapist has confidence in their ability to beat the eating disorder. Parents are reminded that they do know how to feed their child, but that the eating disorder has caused them to doubt themselves. By not providing the parents with specific meal plans or explicit instructions on how to bring about recovery, the parents must figure out what will work best for them. This in turn allows them to rely largely on themselves more than the therapist or treatment team, thus building confidence.

Finally, FBT is a very pragmatic approach with an unwavering initial focus on symptom reduction. In an effort to reduce any potential long-term damage that can be done by the state of malnutrition, there is an emphasis on interrupting the pattern of restricting and quickly restoring the patient to physical health. Problems associated with the eating disorder, such as depressed mood, anxiety, irritability, difficulty concentrating, or social withdrawal, are not addressed directly in 
the first phase of FBT. This is in part to ensure that the focus remains on weight restoration, and in part because many of these secondary problems will resolve themselves with the return to physical health. ${ }^{28}$

\section{Empirical evidence for family-based treatment for AN}

The first randomized controlled trial (RCT) for adolescent AN was conducted by Russell et al at Maudsley Hospital in London. ${ }^{29}$ Eighty female patients with eating disorders between the ages of 14 and 55 years were admitted to an inpatient unit for weight restoration, and upon discharge were randomized to 1 year of family therapy or individual therapy. Due to the heterogeneity in age and diagnosis, participants were divided into four subgroups. One group consisted of adolescents with AN who had a short duration of illness, defined as less than 3 years, and an early age of onset, defined as on or before the age of 18 years. Patients in this subgroup responded better to family therapy, with $90 \%$ of patients falling into "good" or "intermediate" Morgan-Russell outcome categories (based on body weight, menstruation, and presence/absence of bulimic symptoms), whereas only $18 \%$ of patients receiving individual therapy fell into these categories. Furthermore, these gains were maintained at 5-year follow-up. ${ }^{30}$

The first studies outside Maudsley Hospital were conducted by Robin et al. ${ }^{31,32}$ They randomized 37 adolescents with AN to either behavioral family systems therapy (BFST) or ego-oriented individual therapy (EOIT). BFST was similar to FBT, but also incorporated nutritional counseling and cognitive restructuring. In EOIT, the therapist met with the adolescent weekly and had bimonthly collateral sessions with the parents. The focus of treatment was on building the adolescent's ego strength, developing coping skills, helping to individuate from his or her family of origin, and exploring other interpersonal issues and how they relate to eating. Both groups gained weight, although the BFST group gained more than the EOIT group at the end of treatment and 1-year follow-up. At the end of treatment, more patients in BFST than in EOIT had resumed menstruation. Few differences were found between the two groups on measures of eating attitudes, depression, ego functioning, and family relations.

A large RCT randomized 121 adolescents with $\mathrm{AN}$ to either FBT or individual adolescent-focused therapy (AFT; previously referred to as EOIT). ${ }^{31-33}$ The primary outcome variable in this study was full remission, defined as reaching at least $95 \%$ of expected body weight and achieving a mean global score on the Eating Disorder Examination within one standard deviation of community norms. The authors found no differences between the two groups at the end of treatment, but significantly more patients receiving FBT had achieved full remission at 6-month (FBT 40\%, AFT 18\%) and 12-month (FBT 49\%, AFT 23\%) follow-up.

Various forms of FBT have also been studied. Because patients in the Russell et al study ${ }^{29}$ were hospitalized for weight restoration prior to beginning treatment, the study can be conceptualized as a relapse-prevention study. Therefore, efforts were made to examine the efficacy of FBT without prior hospitalization of patients. Le Grange et $\mathrm{al}^{34}$ and Eisler et $\mathrm{al}^{35}$ each compared two forms of family treatment among adolescents with AN. In conjoint family therapy, the adolescent and parents are seen together with the therapist. In separated family therapy, the adolescent is seen alone by the therapist and the parents are then seen separately. Le Grange et al found no differences between the two treatment groups. In a separate study of 40 adolescents with AN, Eisler et al found that approximately $60 \%$ of patients fell into the Morgan-Russell good- or intermediate-outcome categories, with no significant differences between conjoint family therapy and separated family therapy. Patients continued to improve after treatment ended, with $90 \%$ of patients in the good or intermediate categories at 5 -year follow-up. ${ }^{24}$

Lock et al $^{36}$ examined short- and long-term versions of FBT. Eighty-six adolescents with AN were randomized to short-term FBT (ten sessions over 6 months) or long-term FBT (20 sessions over 12 months). No significant differences were found at the end of treatment between the two groups. However, nonintact families and patients with higher levels of eating-related obsessive-compulsive symptoms did better in the long-term version. Specifically, patients with high levels of eating-related obsessive-compulsive symptoms gained more weight in the long-term treatment, and patients from nonintact families had lower global scores on the Eating Disorder Examination if they participated in the long-term treatment. Four years later, $83 \%$ of the 86 patients were followed up, and no significant differences were found between those receiving short- and long-term treatment; $89 \%$ of patients had an expected body weight above $90 \%$, and $90 \%$ were menstruating. No moderators of maintenance of treatment effects were found. ${ }^{37}$

Recently, Le Grange et al compared FBT to an adaptation of FBT called parent-focused treatment (PFT). ${ }^{38}$ In PFT, the adolescent is seen at the beginning of the session by a nurse who weighs the patient, assesses medical stability, and provides brief supportive counseling. This information is then shared with the therapist, who spends the rest of the session 
meeting alone with the parents. A total of 107 patients with AN were randomized to FBT or PFT. The primary outcome variable was full remission, as defined in Lock et al. ${ }^{33}$ Remission rates were higher in PFT (43\%) than in FBT (22\%) at the end of treatment, but the treatment groups did not differ at 6- or 12-month follow-up.

A question arising at this point is: does FBT work because of the involvement of the parents, or is it the specific way in which parents are involved that leads to the treatment's efficacy? This was assessed by Agras et $\mathrm{al}^{39}$ in a study comparing FBT to systemic family therapy (SFT). In SFT, the focus of treatment is on the family system and on the relationships and interactions that develop among family members. Normalization of eating and weight is not a specific focus of treatment, but is addressed if the family raises the issue. The authors found no significant differences between treatment groups in percentage expected body weight at the end of treatment or 1-year follow-up. However, participants in FBT gained weight significantly faster than participants in SFT, and significantly fewer participants in FBT were hospitalized.

There is preliminary evidence to suggest that FBT is effective for older populations in addition to adolescents. ${ }^{40,41}$ In a small study, 22 patients with $\mathrm{AN}$ between the ages of 18 and 26 years participated in a 6-month open trial of FBT for young adults (FBT-Y). ${ }^{41}$ Patients started treatment at a mean body mass index (BMI) of 17.84. At end of treatment and 6-month follow-up, 68\% had a BMI $\geq 19$, and 59\% had a BMI $\geq 19$ at 12 -month follow-up. FBT-Y also resulted in improvements in eating-disorder psychopathology, eatingrelated obsessions and compulsions, other Axis I disorders, and global functioning. However, dropout rates were $41 \%$.

\section{Empirical evidence for family-based treatment for BN}

Although BN generally develops during adolescence, only three RCTs for adolescent BN have been published to date. Le Grange et $\mathrm{al}^{42}$ randomized 80 adolescents to either FBT-BN or individual supportive psychotherapy (SPT). The primary outcome variable was abstinence from binge eating and purging over the previous 28 days. At the end of treatment, more patients in FBT were abstinent (39\%) than in SPT (18\%), and this difference remained significant at 6-month follow-up (FBT 29\%, SPT 10\%). In addition, reduction in symptoms occurred more rapidly for patients receiving FBT.

Schmidt et $\mathrm{al}^{43}$ compared family therapy to cognitive behavioral therapy guided self-care (CBT-GSC) for 85 adolescents. The family therapy in this study was similar to FBT-BN, but differed in that adolescents were allowed to choose "close others" other than parents in their treatment, and a quarter of patients chose this option. The primary outcome variable was abstinence from binge eating and purging over the previous 28 days. At 6 months, more patients in CBT-GSC (42\%) were abstinent from binge eating compared to patients in the family-therapy group (25\%). However, this difference was no longer significant at 12 months, and there were no differences between the groups in frequency of vomiting at either assessment point. The cost of treatment was lower for those assigned to CBT-GSC than to family therapy.

A recent RCT compared FBT-BN with CBT adapted for adolescents (CBT-A). ${ }^{44}$ Abstinence rates were significantly higher for FBT-BN (39.4\%) than for CBT-A (19.7\%) at end of treatment and 6-month follow-up (FBT-BN 44\%, CBT-A 25.4\%), but the difference was no longer significant at 12-month follow-up (FBT-BN 48.5\%, CBT-A 32\%). More participants were hospitalized in CBT-A (21\%) than in FBT-BN (2\%).

\section{Multifamily therapy for AN}

Despite evidence that FBT is an effective form of treatment for adolescents with eating disorders, ${ }^{45}$ not all families respond to treatment, and some need a different or more intensive level of intervention. Multifamily treatment (MFT) for eating disorders has been developed in Dresden, Germany ${ }^{46}$ and London, $\mathrm{UK},{ }^{47}$ and provides a promising alternative for some families. MFT shares a conceptual focus with FBT, in that the family is mobilized to draw on their strengths to help the adolescent recover from the eating disorder. However, MFT offers a more intensive experience, with five to seven families learning from and supporting one another during an introductory evening where families meet a "graduate family" who shares their experience of participating in MFT. This is followed by a 4-day intensive workshop with five to eight follow-up sessions over the next 6-9 months, with separate FBT sessions between follow-up visits as needed. ${ }^{48}$

Thus far, much of the data supporting the use of MFT has consisted of uncontrolled studies. ${ }^{49-51}$ One RCT randomized 169 adolescents to either MFT (MFT-AN) or single-family therapy, although participants randomized to MFT-AN also received individual family meetings as needed. ${ }^{52}$ At the end of treatment, significantly more people in the MFT-AN group fell into good- or intermediate-outcome categories, although this difference was no longer statistically significant at 6-month follow-up. At the end of treatment, there were no differences between the groups in mean percentage BMI, eating-disorder psychopathology, depression, or self-esteem. 
However, at 6-month follow-up, mean percentage BMI was higher in the MFT-AN group.

\section{Family-based treatment in higher levels of care}

The efficacy of FBT has led to efforts to incorporate FBT principles into higher levels of care, such as partial hospitalization programs (PHPs). While it is important to note that FBT is an outpatient form of treatment that cannot be replicated in higher levels of care, it is possible to remain true to the basic tenets of the treatment approach in different treatment settings. Hoste ${ }^{53}$ described the development of a family-based PHP, outlining various considerations that should be taken into account when incorporating FBT principles, such as how to involve parents in treatment and the role that the treatment team should take in supporting the family. Preliminary outcome data for this program show improvements in eating-disorder psychopathology and parental self-efficacy. Other descriptions of family-based PHPs show promising preliminary outcomes. ${ }^{54,55}$ Although from a clinical perspective, some patients seem to require higher levels of care, further studies are needed to determine whether higher levels of care are as effective as empirically supported forms of outpatient therapy, such as FBT or CBT.

\section{Implementation of family-based treatment}

Despite evidence supporting the efficacy of FBT and manualization of the treatment for both $\mathrm{AN}$ and $\mathrm{BN},{ }^{16,17}$ in clinical practice the treatment is often not carried out in accordance with the manual. ${ }^{56}$ Couturier et al ${ }^{56}$ interviewed 40 therapists regarding their treatment of $\mathrm{AN}$, their perspectives on evidence-based practice, and barriers and facilitating factors related to their adoption of FBT. Although over $80 \%$ felt that manualized FBT was well scripted and used it with their own patients, not one therapist practiced the treatment approach with fidelity to the manual.

Themes raised during these interviews were divided into six categories. Interventional barriers to the use of FBT included the time commitment required of therapists and families, the lack of a dietitian on the treatment team, the requirement that the therapist weighs the patient at each session, and the family meal. Organizational factors related to the implementation of FBT included support for the treatment approach on the part of the organization's clinical director or administrator. Interpersonal factors related to reluctance to provide evidence-based practice involved a belief that one approach does not fit all families, and that it is not desirable to commit to a particular form of treatment without considering each family individually. Parental reluctance to engage in FBT and therapist reluctance to use FBT when a parent has an active eating disorder were listed as patient/family barriers to implementing FBT. Systemic barriers to treatment included a lack of awareness in the community about eating disorders and treatment options. Illness factors were also mentioned, as $68 \%$ of therapists reported that the complexity of AN prohibits them from committing to one form of treatment with full fidelity to the model. There was also a belief that patients participating in treatment studies have fewer comorbidities and are not representative of the general population; therefore, using just one form of treatment would not be desirable for more complex patients.

In another study of FBT fidelity, Kosmerly et a $1^{57}$ assessed 117 clinicians who reported using FBT for eating disorders. Cluster analysis revealed that one third of clinicians used techniques not recommended by the FBT manuals, including individual therapy, mindfulness techniques, and motivational work.

Three components of FBT that caused some of the most significant discomfort for therapists in the Couturier et al study ${ }^{56}$ were weighing the patient, the lack of a dietitian, and the family meal. PFT ${ }^{38}$ may be a good alternative for these clinicians, as there is no family meal and a nurse is responsible for weighing the patient. It would also be useful to determine whether these components of FBT are critical to good treatment outcome. Although dismantling studies have not been conducted, Ellison et al ${ }^{58}$ examined some of the core objectives of FBT, including parents taking control of eating, parents being united against the eating disorder, parents not criticizing the patient, externalizing the illness, and sibling support of the patient, and assessed how they were related to treatment outcome. All objectives except for sibling support predicted greater weight gain. A review of the family meal in three different models of family therapy found that firm conclusions cannot yet be drawn about the usefulness of the family meal in treatment. ${ }^{59}$ Questions proposed for future research include: 1) is the family meal a necessary component of treatment?; 2) do all patients (eg, adolescents versus young adults) benefit similarly from the family meal?; 3) what are the components that make up an effective family meal?; 4) how does the therapeutic context influence the potential benefits of the family meal?; and 5) if it is not feasible to have a family meal in session, can other meal-oriented techniques serve the same purpose?

Without dismantling studies to identify the critical components of FBT, it is difficult to state the consequences of 
nonadherence to the treatment manual. What can be said is that nonadherence to the treatment manual will result in the delivery of a non-empirically supported form of treatment. Couturier et $\mathrm{a}^{56}$ point out that it is important to determine in these situations whether one should prescribe following the treatment manual as written and risk rejection of the manual by therapists who do not feel qualified or equipped to implement it, or whether there is room for some flexibility to allow clinicians who are uncertain about components of the treatment to administer it according to their comfort level.

However, it could be argued that discomfort with certain elements of FBT could prove detrimental to treatment outcome. For example, despite the manual clearly stating that the patient should be weighed by the therapist prior to every session, and that weight loss or weight gain sets the tone for the session, over one third of therapists in the Couturier et $a l^{56}$ study said that they did not weigh their FBT patients. Although the reasons for this were not detailed in the study, Waller and Mountford ${ }^{60}$ outlined several reasons given by therapists for not weighing their patients in the context of CBT. These included concerns that it will ruin the therapeutic relationship, a belief that weighing is unnecessary because the patient weighs him/herself or is already weighed by another professional, concern that the patient will be too upset if weighed, stating that there is not enough time in the session to weigh the patient, or believing that the therapist can judge weight gain or weight loss by looking at the patient. FBT therapists in training have also reported being fearful of the reaction of the eating disorder. Not weighing the patient is often done to alleviate either the patient's anxiety or the therapist's anxiety. Either one can be problematic. Although patients may become anxious when being weighed, the FBT therapist is there to support patients and help them process their reaction to being weighed, thereby building therapeutic alliance and rapport. ${ }^{16}$ If the therapist avoids weighing the patient in order to avoid making the patient anxious, this could send a message that the therapist is not equipped to handle the patient's anxiety, thus creating less of a safe and containing therapeutic environment.

Likewise, avoiding therapist anxiety could be equally problematic. Much of an FBT therapist's job is modeling for parents how to interact with the eating disorder and with their child. The therapist models an uncritical, supportive, and compassionate stance toward the patient, along with taking a firm, zero-tolerance approach toward eating-disordered behavior. It will be difficult for therapists to model this firm stance toward the eating disorder if the therapist is scared of it. If the therapist avoids weighing the patient because of fear of the wrath of the eating disorder, this therapist will not be as effective in treatment.

The issue of treatment implementation is an important one. Effective therapies do not help patients if they are not effectively implemented. The majority of therapists in Couturier et $\mathrm{al}^{56}$ requested additional training in FBT. Additional studies are needed to assess whether the level of training in FBT improves treatment adherence.

\section{Adaptations to family-based treatment}

Even when practiced with full adherence to the manual, FBT is not effective for all families. Now that the efficacy of the treatment has been established, research can turn to the question of what to do with families for whom FBT does not work. In a study of early response to treatment, it was found that $2.88 \%$ weight gain (approximately $2.2 \mathrm{~kg}$ ) by session 4 was the strongest predictor of posttreatment remission. ${ }^{61}$ Lock et $\mathrm{al}^{62}$ examined the feasibility of an adaptive treatment intended to enhance parental self-efficacy in families of patients who were early nonresponders to therapy. Forty-five patients with AN were randomized to either FBT $(n=10)$ or FBT with intensive parental coaching (IPC; $n=35$ ) if patients did not gain $2.2 \mathrm{~kg}$ by session 4 . In addition to standard FBT, IPC included three additional sessions that focused on mealtime coaching. In the first of these three additional sessions, the failure to achieve adequate weight gain is presented to the family as a crisis situation, and the family is reinvigorated to make the behavioral changes necessary to result in weight restoration. In the second IPC session, the therapist meets the parents alone to identify barriers to successful weight restoration. The third session consists of a second family meal, after which point manualized FBT resumes.

There were no differences in attrition rates, number of sessions, treatment suitability and expectancy ratings, or clinical outcomes between the two treatment groups, indicating the feasibility and acceptability of IPC. Mothers of patients who responded early to treatment had higher levels of self-efficacy than nonresponders at session 2, but after the additional IPC sessions, parental self-efficacy scores no longer differed between the two groups. The weight trajectories of the IPC arm were also compared to a group of FBT nonresponders from a different RCT $(n=38) \cdot{ }^{39}$ At baseline, the two groups' average weight was similar. After session 4, when IPC was introduced in the Lock et al study, ${ }^{62}$ the weight trajectories begin to differ, and at the end of treatment patients in the IPC arm were significantly higher in terms of weight than patients from the Agras et al RCT. Data must be interpreted 
with caution, given the small sample size, but these preliminary results suggest that adaptive FBT is feasible and may be effective in bringing about weight restoration for early treatment nonresponders.

\section{Eating-disorder caregivers}

Additional parental coaching may be particularly welcome, given the stress that can accompany caring for an individual with an eating disorder. Caregivers of people with eating disorders experience high levels of caregiving burden and psychological distress. ${ }^{63-67}$ Although FBT can be an intense and challenging process for parents, parents' experience of FBT has not been well documented. Anecdotal accounts suggest that it can be quite difficult. ${ }^{68,69}$ An exploration of blogs of mothers engaged in FBT found two main themes: the importance of social support and shifts in parenting. ${ }^{70}$ Mothers described formal support from members of their treatment team, as well as informal support, such as support from online forum members or significant others, as being key to their caregiving experiences. They also discussed the shift in parenting that is often required by FBT, in the sense that they became much more involved in their child's life than they were prior to the onset of the eating disorder.

Given the importance of support from others, it is worthwhile to consider ways to offer assistance to parents going through FBT. Rhodes et al ${ }^{71}$ evaluated parent-to-parent consultation for 20 families going through FBT. Ten families received standard treatment, and ten received additional parent-to-parent consultation. The consultation involved a joint interview with parents new to FBT and parents who had successfully completed treatment. Graduate parents were asked to share their experiences of treatment and of the weight-restoration process, and to discuss how they facilitated the recovery of their children. Parents in parentto-parent consultation felt that the experience made them feel less alone, enabled them to reflect more on family roles and interactions, and gave them confidence that they may be similarly successful in treatment. The consultation did not lead to differences in percentage of ideal body weight at the end of treatment, but it did lead to a small increase in the rate of weight restoration. ${ }^{72}$

Online support has also been offered to parents going through FBT. ${ }^{73}$ Thirteen caregivers participated in 15 weekly online therapist-guided chat sessions. Participants reported a high degree of satisfaction with the group (91.7\%), and the majority said it helped them cope with their child's eating disorder and they would recommend the chat group to another caregiver.
Caregiving burden has been found to be associated with high expressed emotion (EE). ${ }^{74} \mathrm{EE}$ is a measure of a relative's attitudes and behaviors toward an ill family member across five domains: critical comments, hostility, emotional overinvolvement, positive remarks, and warmth. ${ }^{75}$ Relatives who score high on critical comments, hostility, or emotional overinvolvement are considered high on EE. High parental EE is associated with poor treatment outcome in families of patients with $\mathrm{AN},{ }^{76,77}$ whereas parental warmth is associated with good treatment outcome. ${ }^{78}$ Several caregiver interventions have been developed that result in a reduction in EE. ${ }^{74,79,80}$ It would be worthwhile to determine whether these interventions can be used to improve treatment outcome in FBT specifically.

\section{Conclusion}

FBT is considered by some to be the first-line treatment for adolescents with $\mathrm{AN}$, and evidence is accumulating for its use with adolescents with BN. FBT has been expanded upon such that its principles are now included in multifamily therapy, as well as in higher levels of care. The development of FBT and its reliance on families as the primary agents of change in the recovery process has significantly changed the landscape of treatment for adolescents with eating disorders. FBT, however, does not work for all families. Future research is needed to identify better the families for whom FBT does not work, determine adaptations to FBT that may increase its efficacy for treatment nonresponders, develop ways to improve treatment adherence among clinicians offering FBT, and find ways to support parents during treatment better.

\section{Acknowledgment}

The author would like to thank Daniel Le Grange, PhD for his comments on an earlier version of this manuscript.

\section{Disclosure}

Dr Rienecke receives consulting fees from the Training Institute for Child and Adolescent Eating Disorders, LLC, and reports no other conflicts of interest in this work.

\section{References}

1. Stice E, Marti CN, Shaw H, Jaconis M. An 8-year longitudinal study of the natural history of threshold, subthreshold, and partial eating disorders from a community sample of adolescents. J Abnorm Psychol. 2009;118:587-597.

2. Swanson SA, Crow SJ, le Grange D, Swendsen J, Merikangas KR. Prevalence and correlates of eating disorders in adolescents: results from the national comorbidity survey replication adolescent supplement. Arch Gen Psychiatry. 2011;68:714-723.

3. Bühren K, Schwarte R, Fluck F, et al. Comorbid psychiatric disorders in female adolescents with first-onset anorexia nervosa. Eur Eat Disord Rev. 2014;22:39-44. 
4. Jenkins P, Hoste RR, Meyer C, Blissett J. Eating disorders and quality of life: a review of the literature. Clin Psychol Rev. 2011;31:113-121.

5. Arcelus J, Mitchell AJ, Wales J, Nielsen S. Mortality rates in patients with anorexia nervosa and other eating disorders: a meta-analysis of 36 studies. Arch Gen Psychiatry. 2011;68:724-731.

6. Chesney E, Goodwin GM, Fazel S. Risks of all-cause and suicide mortality in mental disorders: a meta-review. World Psychiatry. 2014;13: 153-160.

7. American Psychiatric Association. Diagnostic and Statistical Manual of Mental Disorders. 5th ed. Arlington, VA: American Psychiatric Publishing; 2013.

8. Norris ML, Robinson A, Obeid N, Harrison M, Spettigue W, Henderson K. Exploring avoidant/restrictive food intake disorder in eating disordered patients: a descriptive study. Int J Eat Disord. 2014;47: 495-499.

9. Nicely TA, Lane-Loney S, Masciulli E, Hollenbeak CS, Ornstein RM. Prevalence and characteristics of avoidant/restrictive food intake disorder in a cohort of young patients in day treatment for eating disorders. J Eat Disord. 2014;2:21.

10. Eddy KT, Doyle AC, Hoste RR, Herzog DB, le Grange D. Eating disorder not otherwise specified in adolescents. J Am Acad Child Adolesc Psychiatry. 2008;47:156-164.

11. Peebles R, Hardy KK, Wilson JL, Lock JD. Medical compromise in eating disorders not otherwise specified: are diagnostic criteria for eating disorders markers of severity? Pediatrics. 2010;125:e1193-e1201.

12. Le Grange D, Binford RB, Peterson CB, et al. DSM-IV threshold versus subthreshold bulimia nervosa. Int J Eat Disord. 2006;39:462-467.

13. Le Grange D, Crosby RD, Engel SC, et al. DSM-IV-defined anorexia nervosa versus subthreshold anorexia nervosa (EDNOS-AN). Eur Eat Disord Rev. 2013;21:1-7.

14. Stice E, Marti CN, Rohde P. Prevalence, incidence, impairment, and course of the proposed DSM-5 eating disorder diagnoses in an 8-year prospective community study of young women. J Abnorm Psychol. 2013;122:445-457.

15. Herpertz-Dahlmann B. Adolescent eating disorders: update on definitions, symptomatology, epidemiology, and comorbidity. Child Adolesc Psychiatr Clin N Am. 2015;24:177-196.

16. Lock J, le Grange D. Treatment Manual for Anorexia Nervosa: A FamilyBased Approach. 2nd ed. New York: Guilford; 2013.

17. Le Grange D, Lock J. Treating Bulimia in Adolescents: A Family-Based Approach. New York: Guilford; 2007.

18. Rienecke RD, Sim L, Lock J, le Grange D. Patterns of expressed emotion in adolescent eating disorders. $J$ Child Psychol Psychiatry. 2016;57:1407-1413.

19. Sweeney C, Loeb KL, Parter A, Hail L, Zucker N. Family-based treatment for prodromal anorexia nervosa. In: Loeb KL, le Grange D, Lock J, editors. Family Therapy for Adolescent Eating and Weight Disorders: New Applications. New York: Routledge; 2015:157-176.

20. Loeb KL, Celio Doyle A, Anderson K, et al. Family-based treatment for child and adolescent overweight and obesity: a transdevelopmental approach. In: Loeb KL, le Grange D, Lock J, editors. Family Therapy for Adolescent Eating and Weight Disorders: New Applications. New York: Routledge; 2015:177-229.

21. Fitzpatrick KK, Forsberg SE, Colborn D. Family-based therapy for avoidant restrictive food intake disorder: families facing food neophobias. In: Loeb KL, le Grange D, Lock J, editors. Family Therapy for Adolescent Eating and Weight Disorders: New Applications. New York: Routledge; 2015:256-276.

22. Le Grange D, Eisler I, Dare C, Hodes M. Family criticism and selfstarvation: a study of expressed emotion. J Fam Ther. 1992;14:177-192.

23. Szmukler GI, Eisler I, Russell GF, Dare C. Anorexia nervosa, parental "expressed emotion", and dropping out of treatment. Br J Psychiatry. 1985; 147:265-271.

24. Eisler I, Simic M, Russell G, Dare C. A randomized controlled trial of two forms of family therapy in adolescent anorexia nervosa: a five-year follow-up. J Child Psychol Psychiatry. 2007;48:552-560.
25. van Furth EF, van Strien DC, Martina LM, van Son MJ, Hendrickx JJP, van Engeland $\mathrm{H}$. Expressed emotion and the prediction of outcome in adolescent eating disorders. Int J Eat Disord. 1996;20:19-31.

26. Rienecke RD, Accurso EC, Lock J, le Grange D. Expressed emotion, family functioning, and treatment outcome for adolescents with anorexia nervosa. Eur Eat Disord Rev. 2016;24:43-51.

27. Le Grange D, Lock J, Loeb K, Nicholls, D. Academy for Eating Disorders position paper: the role of the family in eating disorders. Int $J$ Eat Disord. 2010;43:1-5.

28. Keys A, Brožek J, Henschel A, Mickelsen O, Taylor HL. The Biology of Human Starvation. Minneapolis: University of Minnesota Press; 1950.

29. Russell GF, Szmukler GI, Dare C, Eisler I. An evaluation of family therapy in anorexia nervosa and bulimia nervosa. Arch Gen Psychiatry. 1987;44:1047-1056.

30. Eisler I, Dare C, Russell GF, Szmukler GI, le Grange D, Dodge E. Family and individual therapy in anorexia nervosa: a five-year follow-up. Arch Gen Psychiatry. 1997;54:1025-1030.

31. Robin AL, Siegel PT, Koepke T, Moye AW, Tice S. Family therapy versus individual therapy for adolescent females with anorexia nervosa. $J$ Dev Behav Pediatr. 1994;15:111-116.

32. Robin AL, Siegel PT, Moye AW, Gilroy M, Dennis AB, Sikand A. A controlled comparison of family versus individual therapy for adolescents with anorexia nervosa. J Am Acad Child Adolesc Psychiatry. 1999;38:1482-1489.

33. Lock J, le Grange D, Agras WS, Moye A, Bryson SW, Jo B. Randomized clinical trial comparing family-based treatment with adolescent-focused individual therapy for adolescents with anorexia nervosa. Arch Gen Psychiatry. 2010;67:1025-1032.

34. Le Grange D, Eisler I, Dare C, Russell GF. Evaluation of family treatments in adolescent anorexia nervosa: a pilot study. Int J Eat Disord. 1992;12:347-357.

35. Eisler I, Dare C, Hodes M, Russell G, Dodge E, le Grange D. Family therapy for adolescent anorexia nervosa: the results of a controlled comparison of two family interventions. J Child Psychol Psychiatry. 2000;41: 727-736.

36. Lock J, Agras WS, Bryson S, Kraemer HC. A comparison of short- and long-term family therapy for adolescent anorexia nervosa. J Am Acad Child Adolesc Psychiatry. 2005;44:632-639.

37. Lock J, Couturier J, Agras WS. Comparison of long-term outcomes in adolescents with anorexia nervosa treated with family therapy. $J \mathrm{Am}$ Acad Child Adolesc Psychiatry. 2006;45:666-672.

38. Le Grange D, Hughes EK, Court A, Yeo M, Crosby RD, Sawyer SM. Randomized clinical trial of parent-focused treatment and family-based treatment for adolescent anorexia nervosa. $J$ Am Acad Child Adolesc Psychiatry. 2016;55:683-692.

39. Agras WS, Lock J, Brandt $\mathrm{H}$, et al. Comparison of 2 family therapies for adolescent anorexia nervosa: a randomized parallel trial. JAMA Psychiatry. 2014;71:1279-1286.

40. Chen EY, le Grange D, Celio Doyle A, et al. A case series of family-based therapy for weight restoration in young adults with anorexia nervosa. $J$ Contemp Psychother. 2010;40:219-224.

41. Chen EY, Weissman JA, Zeffiro TA, et al. Family-based therapy for young adults with anorexia nervosa restores weight. Int J Eat Disord. 2016;49:701-707.

42. Le Grange D, Crosby RD, Rathouz PJ, Leventhal BL. A randomized controlled comparison of family-based treatment and supportive psychotherapy for adolescent bulimia nervosa. Arch Gen Psychiatry. 2007;64:1049-1056.

43. Schmidt U, Lee S, Beecham J, et al. A randomized controlled trial of family therapy and cognitive behavior therapy guided self-care for adolescents with bulimia nervosa and related disorders. Am J Psychiatry. 2007;164:591-598.

44. Le Grange D, Lock J, Agras WS, Bryson SW, Jo B. Randomized clinical trial of family-based treatment and cognitive-behavioral therapy for adolescent bulimia nervosa. J Am Acad Child Adolesc Psychiatry. 2015;54:886-894. 
45. Couturier J, Kimber M, Szatmari P. Efficacy of family-based treatment for adolescents with eating disorders: a systematic review and metaanalysis. Int J Eat Disord. 2013;46:3-11.

46. Scholz M, Asen KE. Multiple family therapy with eating disordered adolescents. Eur Eat Disord Rev. 2001;9:33-42.

47. Dare C, Eisler I. A multi-family group day treatment programme for adolescent eating disorders. Eur Eat Disord Rev. 2000;8:4-18.

48. Fairbairn P, Simic M, Eisler I. Multifamily therapy for adolescent anorexia nervosa. In: le Grange D, Lock J, editors. Eating Disorders in Children and Adolescents: A Clinical Handbook. New York: Guilford; 2011:243-261.

49. Hollesen A, Clausen L, Rokkedal K. Multiple family therapy for adolescents with anorexia nervosa: a pilot study of eating disorder symptoms and interpersonal functioning. J Fam Ther. 2013;35:53-67.

50. Gabel K, Pinhas L, Eisler I, Katzman D, Heinmaa M. The effect of multiple family therapy on weight gain in adolescents with anorexia nervosa: pilot data. J Can Acad Child Adolesc Psychiatry. 2014;23: 196-199.

51. Salaminiou E, Campbell M, Simic M, Kuipers E, Eisler I. Intensive multi-family therapy for adolescent anorexia nervosa: an open study of 30 families. J Fam Ther. Epub 2015 Jul 3.

52. Eisler I, Simic M, Hodsoll J, et al. A pragmatic randomised multi-centre trial of multifamily and single family therapy for adolescent anorexia nervosa. BMC Psychiatry. 2016;16:422.

53. Hoste RR. Incorporating family-based therapy principles into a partial hospitalization programme for adolescents with anorexia nervosa: challenges and considerations. J Fam Ther. 2015;37:41-60.

54. Girz L, Robinson AL, Foroughe M, Jasper K, Boachie A. Adapting family-based therapy to a day hospital programme for adolescents with eating disorders: preliminary outcomes and trajectories of change. $J$ Fam Ther. 2013;35:102-120.

55. Henderson K, Buchholz A, Obeid N, et al. A family-based eating disorder day treatment program for youth: examining the clinical and statistical significance of short-term treatment outcomes. Eat Disord. 2014;22:1-18.

56. Couturier J, Kimber M, Jack S, Niccols A, Van Blyderveen S, McVey G. Understanding the uptake of family-based treatment for adolescents with anorexia nervosa: therapist perspectives. Int J Eat Disord. 2013;46:177-188.

57. Kosmerly S, Waller G, Robinson AF. Clinician adherence to guidelines in the delivery of family-based therapy for eating disorders. Int J Eat Disord. 2015;48:223-229.

58. Ellison R, Rhodes P, Madden S, et al. Do the components of manualized family-based treatment for anorexia nervosa predict weight gain? Int J Eat Disord. 2012;45:609-614.

59. Cook-Darzens S. The role of family meals in the treatment of eating disorders: a scoping review of the literature and implications. Eat Weight Disord. 2016;21:383-393.

60. Waller G, Mountford VA. Weighing patients within cognitive-behavioural therapy for eating disorders: how, when and why. Behav Res Ther. 2015;70:1-10

61. Doyle P, le Grange D, Loeb K, Doyle AC, Crosby R. Early response to family-based treatment for adolescent anorexia nervosa. Int J Eat Disord. 2010;43:659-662.

62. Lock J, le Grange D, Agras WS, et al. Can adaptive treatment improve outcomes in family-based therapy for adolescents with anorexia nervosa? Feasibility and treatment effects of a multi-site treatment study. Behav Res Ther. 2015;73:90-95.
63. Graap H, Bleich S, Wilhelm J, et al. Needs and demands of the relatives of patients with anorexia or bulimia nervosa. Neuropsychiatr. 2005;19: 155-161.

64. Perkins S, Winn S, Murray J, Murphy R, Schmidt U. A qualitative study of the experience of caring for a person with bulimia nervosa, part 1: the emotional impact of caring. Int J Eat Disord. 2004;36:256-268.

65. Treasure J, Murphy T, Szmukler G, Todd G, Gavan K, Joyce J. The experience of caregiving for severe mental illness: a comparison between anorexia nervosa and psychosis. Soc Psychiatry Psychiatr Epidemiol. 2001;36:343-347.

66. Winn S, Perkins S, Murray J, Murphy R, Schmidt U. A qualitative study of the experience of caring for a person with bulimia nervosa, part 2: carers' needs and experiences of services and other support. Int J Eat Disord. 2004;36:269-279.

67. Zabala MJ, Macdonald P, Treasure J. Appraisal of caregiving burden, expressed emotion and psychological distress in families of people with eating disorders: a systematic review. Eur Eat Disord Rev. 2009; $17: 338-349$.

68. Brown H. A parent's perspective on family treatment. In: le Grange D, Lock J, editors. Eating Disorders in Children and Adolescents: A Clinical Handbook. New York: Guilford; 2011:457-460.

69. Hopf R, Hoste R, Pariseau C. Parent support as an adjunct to family therapy. In: Loeb K, le Grange D, Lock J, editors. Family Therapy for Adolescent Eating and Weight Disorders: New Applications. New York: Routledge; 2015:139-154.

70. LaMarre A, Robson J, Dawczyk A. Mothers' use of blogs while engaged in family-based treatment for a child's eating disorder. Fam Syst Health. 2015;33:390-394.

71. Rhodes P, Brown J, Madden S. The Maudsley model of family-based treatment for anorexia nervosa: a qualitative evaluation of parent-toparent consultation. J Marital Fam Ther. 2009;35:181-192.

72. Rhodes P, Baillee A, Brown J, Madden S. Can parent-to-parent consultation improve the effectiveness of the Maudsley model of family-based treatment for anorexia nervosa? A randomized control trial. J Fam Ther. 2008;30:96-108.

73. Hopf RB, le Grange D, Moessner M, Bauer S. Internet-based chat support groups for parents in family-based treatment for adolescent eating disorders: a pilot study. Eur Eat Disord Rev. 2013;21:215-223.

74. Sepulveda AR, Todd G, Whitaker W, Grover M, Stahl D, Treasure J. Expressed emotion in relatives of patients with eating disorders following skills training program. Int J Eat Disord. 2010;43:603-610.

75. Brown GW, Birley JL, Wing JK. Influence of family life on the course of schizophrenic disorders: a replication. Br J Psychiatry. 1972;121:241-258.

76. Le Grange D, Eisler I, Dare C, Hodes M. Family criticism and self-starvation: a study of expressed emotion. J Fam Ther. 1992;14:177-192.

77. Szmukler GI, Eisler I, Russell GF, Dare C. Anorexia nervosa, parental "expressed emotion" and dropping out of treatment. Br J Psychiatry. 1985;147:265-271.

78. Le Grange D, Hoste RR, Lock J, Bryson SW. Parental expressed emotion of adolescents with anorexia nervosa: outcome in family-based treatment. Int J Eat Disord. 2011;44:731-734.

79. Gísladóttir M, Svavarsdóttir EK. Educational and support intervention to help families assist in the recovery of relatives with eating disorders. J Psychiatr Ment Health Nurs. 2011;18:122-130.

80. Uehara T, Kawashima Y, Goto M, Tasaki SI, Someya T. Psychoeducation for the families of patients with eating disorders and changes in expressed emotion: a preliminary study. Compr Psychiatry. 2001;42:132-138. 
Adolescent Health, Medicine and Therapeutics is an international, peer-reviewed, open access journal focusing on health, pathology, and treatment issues specific to the adolescent age group. All aspects of health maintenance, preventative measures and disease treatment interventions are addressed within the journal and practitioners from all disciplines are invited to submit their work as well as healthcare researchers and patient support groups. This journal is included in PubMed. The manuscript management system is completely online and includes a very quick and fair peer-review system. Visit http://www.dovepress.com/testimonials. php to read real quotes from published authors.

Submit your manuscript here: http://www.dovepress.com/adolescent-health-medicine-and-therapeutics-journal 